\title{
A pintura em pânico, a fotomontagem e a pós-modernidade
}

\section{Panic painting, photomontage and postmodernity}

\author{
Lorena Machado Macêdo Oliveira \\ Mestranda do Programa de Pós-Graduação em Letras e Artes da Universidade do Estado do Amazonas (PPGLA/UEA) - \\ shintaeien@gmail.com - orcid.org/0000-0001-5764-9327 \\ Luciane Viana Barros Páscoa \\ Doutora em História Cultural pela Universidade do Porto (Portugal) - \\ luciane.pascoa@gmail.com - orcid.org/0000-0001-7751-0189/
}

\section{Resumo}

Observando as indicações de Erwin Panofsky (1955) sobre o modo pelo qual uma obra de arte pode ser interpretada, este artigo propõe uma aproximação entre o livro de fotomontagens A pintura em pânico (1943), do poeta Jorge de Lima (1893-1953), e o conceito de pós-modernidade desenvolvido por Gianni Vattimo em A sociedade transparente (1989). Para tanto, contextualiza-se a fotomontagem de vanguarda como uma subversão do próprio princípio fotográfico enquanto análogo da realidade, e ainda como uma afronta à pintura enquanto método canônico de composição pictórica. Recorre-se ainda, à aproximação estabelecida por Gianni Vattimo entre os conceitos de shock em Walter Benjamin (1955), e o stoss de Martin Heidegger (1977), para sugerir que a fotomontagem transcendeu o periodo no qual surgiu e funciona como uma espécie de analogia à condição pós-moderna, que é, sobretudo, multiforme.

Palavras-chave: Fotografia - Efeitos especiais. Fotomontagem. Lima, Jorge de, 1893-1953

\begin{abstract}
Observing Erwin Panofsky's (1955) indications about the way to interpret a work of art, this article proposes an approximation between A pintura em pânico (1943) photomontages book, composed by poet Jorge de Lima (1893-1953), and the postmodernity's concept developed by Gianni Vattimo in The transparent society (1989). To this end, the avant-garde photomontage is understood as a subversion of the photographic principle itself considered as analogue to reality, and also as a rupture to painting as a pictorial composition's canonic method. We also resort to the Gianni Vattimo's established approximation between the concepts of shock in Walter Benjamin (1955) and Martin Heidegger's stoss (1977), in order to suggest photomontage transcended its period and works as analogue to post modern's condition, which is, above all, multiform.
\end{abstract}

Keywords: Photography - Special effects. Photomontages. Lima, Jorge de, 1893-1953.

Recebido em: $12 / 03 / 2020$

Aceito em: 13/05/2020 


\section{INTRODUÇÃO}

Segundo Panofsky (2014, p.23), o homem distingue-se fundamentalmente dos outros animais por ser capaz de registrar sua existência material, intencionalmente, através da expressão de lembranças e percepções ${ }^{1}$, ou seja, o registro de si. O humanismo, por sua vez, entendido como atitude $^{2}$, está relacionado à percepção de que a racionalidade e a liberdade são autênticos valores humanos, do mesmo modo que a falibilidade e fragilidade são limitações inerentes à vida. Desta premissa resultam os dois postulados intrínsecos à atitude humanista, que são, justamente, a responsabilidade e a tolerância. (IDEM, p.21) As proposições de Panofsky sobre o modo pelo qual se pode investigar e analisar uma obra de arte têm fundamento na referida atitude humanista, e propõe, a quem pretenda interpretar uma obra, a adoção de uma atitude cautelosa mediante os inevitáveis obstáculos aos quais estão sujeitas as investigações de qualquer espécie de documento. (IDEM, p. 26-27) Em vista disso, o método iconológico propõe, através da identificação dos motivos e conceitos de uma obra, a aproximação do contexto no qual ela se insere, possibilitando, assim, a identificação daquilo que Cassirer chamou de "valores simbólicos". Valores estes que Panofsky classificou como "significado intrínseco" e que, justamente, são somente acessíveis através da compreensão de que o mundo dos motivos e das imagens que residem numa obra dizem respeito à determinada cultura, e apenas podem ser apreendidos a partir do entendimento do universo fundado pela obra. Deste modo, propõe-se aqui, observando as indicações de Panofsky, uma aproximação que nos foi suscitada justamente a partir do referido método, no sentido de situar o livro de fotomontagens do poeta Jorge de Lima (1893-1953), A pintura em pânico (1943) (Fig.1), pela técnica e teoria que Ihes são inerentes, como análogo à consciência pós-moderna, tal como conceituada pelo filósofo italiano Gianni Vattimo.

\footnotetext{
${ }^{1}$ Através da poesia, da música, da pintura, ou de qualquer expressão que corporifique a significação que se pretende.

2 "Não é tanto um movimento como uma atitude, que pode ser definida como a convicção da dignidade do homem..." (PANOFSKY, 2014, p.21)
} 


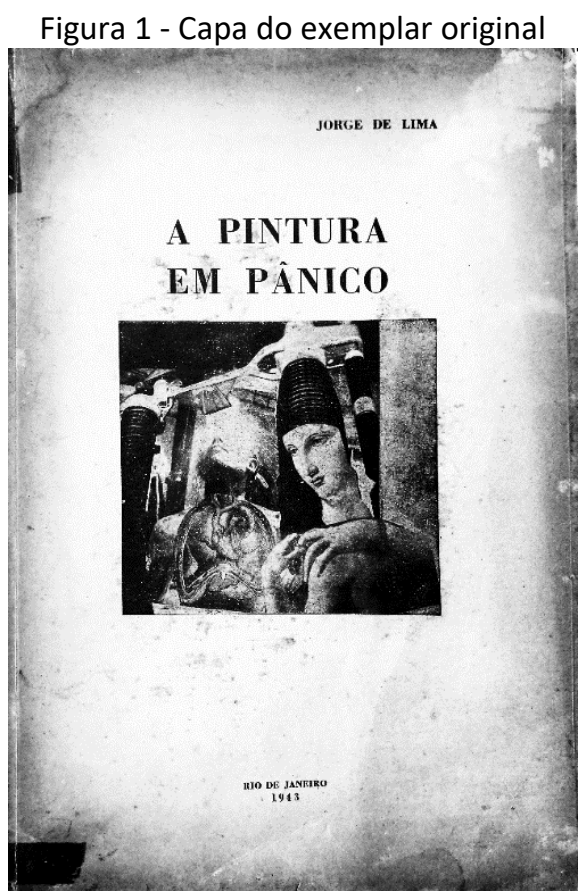

Fonte: Biblioteca Brasiliana Guita e José Mindlin

Em 1943, Jorge de Lima publicou, em uma tiragem de duzentos e cinquenta exemplares, um livro contendo 41 fotomontagens acompanhadas por dísticos, sob o título A pintura em pânico. Os exemplares foram numerados de 1 a 250 e rubricados pelo poeta. A obra original contém um prefácio, a Nota Liminar, assinado por Murilo Mendes, que, em tom libertário, alude a pelo menos dois movimentos da vanguarda europeia. Entre os dias 15 de março e 03 de maio de 2010, ocorreu na Galeria 1 da Caixa Cultural Rio de Janeiro, sob a curadoria de Simone Rodrigues, uma exposição inédita que reproduziu integralmente as fotomontagens compostas por Jorge de Lima entre os anos de 1930-40, contando, inclusive, com as 11 chapas originais que pertenceram à Mário de Andrade e encontram-se no arquivo pessoal deste, hoje alocado no Instituto de Estudos Brasileiros (IEB) da Universidade do Estado de São Paulo. É importante mencionar que a reprodução integral das fotomontagens através da exposição realizada pela Caixa Cultural, bem como em catálogo, possibilitou maior aproximação do público com esta que é uma das grandes produções artísticas do Modernismo brasileiro e, ainda, um documento de grande importância no contexto da obra de Jorge de Lima. 


\section{A PINTURA EM PÂNICO E A FOTOMONTAGEM}

Segundo Dawm Ades, em Photomontage (1976, p.7), a fotomontagem, enquanto técnica, surge ao mesmo tempo que a fotografia, podendo ser entendida, assim, como um dos princípios da fotografia, já que o desenho fotogênico, desenvolvido e aprimorado por Talbot (1800-1887) no século XIX, é, em essência, um processo de fotomontagem. Tal técnica, que consistia na fixação de uma imagem através da sobreposição de objetos sobre uma superfície emulsionada, foi redescoberta e ampliada no século XX através dos experimentos de Man Ray (1890-1976), Christian Schad (18941982) e Moholy-Nagy (1895-1946). As primeiras manipulações fotográficas, por sua vez, ocorreram como fenômenos acidentais de revelação, que resultavam em impressões de partes de uma imagem em outra, o que acontecia sobretudo por conta da lavagem inadequada das placas de colóquio. Tais imprevistos logo passaram a ser experimentados de modo intencional, no intuito de formarem novas composições por meio da impressão de vários negativos em uma mesma chapa. As técnicas utilizadas eram diversas, tais como "fotomontagens através de recortes, de super-exposição, de sobreimpressão, da repetição do mesmo negativo, da dupla impressão ou da combinação de vários destes processos." (FERNANDES, 2012, p.41) As imagens que resultavam destes procedimentos ficaram conhecidas como impressões combinadas, e, em meados do século XIX, no contexto europeu, surgiram várias publicações, chamadas de divertimentos, que se dedicavam à veiculação de tais composições. Deste modo, a fotomontagem enquanto técnica surgiu dentro de um contexto popular e com ares de entretenimento, onde foi, por isso mesmo, explorada e até bastante divulgada através da publicação em cartazes, panfletos e postais. (ADES, 1976, p.11)

Entretanto, posteriormente, a técnica de manipulação das imagens fotográficas, tal como se desenvolve no contexto dos movimentos de vanguarda do século XX, esteve ligada a uma tendência muito mais subversiva no campo teórico e, por isso, expandiu aquela proposta experimentalista inaugurada no XIX. O termo "fotomontagem", aliás, surgiu somente após a primeira guerra, quando os dadaístas de Berlim e os construtivistas russos buscavam distinguir suas criações, que se utilizavam de fragmentos fotográficos, da técnica da collage experimentada pelo cubismo sintético. No contexto específico do Surrealismo, a presença de Max Ernst (1891-1976) foi de suma importância para a incorporação e adaptação da fotomontagem aos ideais do movimento, já que o francês de origem 
alemã havia participado efetivamente do dadaísmo e estudado filosofia e psiquiatria ${ }^{3}$, matérias essas que constituem alguns dos pilares do movimento teorizado por André Breton (1896-1966). Além disso, Max Ernst serviu durante a primeira guerra mundial, o que certamente imprimiu-lhe certa percepção fragmentada da realidade, além é claro, da influência dos efeitos irreparáveis que a barbárie acarreta à alma humana. A presença de Max Ernst, aliás, é tão cara para o surrealismo quanto é para a concepção estética de A pintura em pânico, de modo que tal influência é precisamente indicada por Murilo Mendes na Nota Liminar:

O conselho veio de Rimbaud: desarticular os elementos. Aplicados ao desenho e ao ballet, tal princípio provocou excelentes realizações. Por exemplo, La femme 100 têtes, de Max Ernst e Bacanal de Salvador Dalí. O livro de Max Ernst inspirava-me. Faltavam-me, porém, a paciência, a perseverança. Jorge de Lima tem tudo isto, e mais ainda. Começamos juntos o trabalho. Mas dentre em breve ele ficava sozinho.

Figura 2 - La femme 100 têtes.

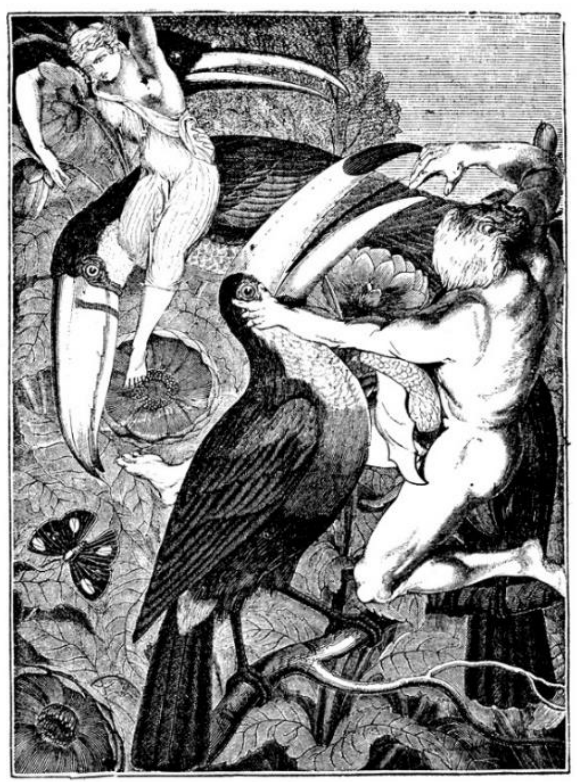

L'œil sans yeux, la femme 100 tètes et Loplop retournent à l'état sauvage et recouvent de feuilles fraiches les yeux de leurs fidèles oiseaux.

Fonte: Max Ernst (1929).

Max Ernst iniciou suas experiências com a colagem por volta dos anos 20, período em que ilustrou os livros Répétitions (1922) e Les Malheurs des immortels (1922) de Pául Éluard, onde fotomontagens acompanham poemas ${ }^{4}$. Além disso, as obras La Femme 100 têtes (1929) (Fig.2), Rêve d'une petite fille qui voulut entrer au Carmel (1930) e Une Semaine de Bonté ou les sept éléments

\footnotetext{
${ }^{3}$ Durante este período, Max Ernst visitou alguns sanatórios e ficou fascinado pela arte produzida por pacientes em estado de delírio, pela "arte dos psicóticos". (Sacchettin, 2018, p.83.)

${ }^{4}$ Semelhante ao que acontece quando Jorge de Lima ilustra a capa de A poesia em pânico (1937) de Murilo Mendes. ${ }^{5}$ (Idem, ibidem.)
} 
capitaux (1934), de Max Ernst, são intituladas roman-collages (romances-colagem), o que indica a possibilidade de que pode ele ter compreendido a fotomontagem relacionada a uma espécie de expansão da criação literária. (SACCHETTIN, 2018, p.84) Segundo Sacchettin (p.84), é justamente por tal razão que Jorge de Lima cita Ernst, quando, ao ser indagado sobre o significado e sentido de suas próprias composições, associa fotomontagem e poesia:

Vocês vejam: cada fotografia dessas vale um poema, não vale? Pois é a intenção de Max Ernst. Com diversos elementos isolados que nada significam, produzir um conjunto que tem o dom de provocar uma sensação poética ${ }^{5}$.

Assim como Max Ernst, Jorge de Lima parece ter compreendido a fotomontagem enquanto extensão da criação literária, tanto que assim explica o seu processo:

Como faço isso? Ora, muito simplesmente: pego uma porção de objetos, de coisas, de ideias, uma revista, um jornal, uma escultura, elementos que isolados não tem a menor significação. Junto e produzo alguma coisa que podemos chamar de um poema ${ }^{6}$.

O poeta indica, porém, em que sentido suas composições diferem das dos surrealistas, ao dizer que, enquanto "Ernst e seus seguidores" entendiam as fotomontagens como "gravuras suprarealistas", ele, por sua vez, criava "fotografias com uma direção lírica e romântica"7. Além disso, segundo Sacchettin (2018, p.43), não parecia haver, da parte de Jorge de Lima, uma atitude no sentido de pretender afrontar ou polemizar através da publicação de A pintura em pânico (1943), como era frequentemente a intenção dos dadaístas e surrealistas, de modo que, certa vez, ao ser indagado sobre a dificuldade de compreensão de suas fotomontagens - em uma das pouquíssimas vezes em que o poeta se pronunciou sobre elas -, a resposta de Jorge de Lima, ao invés de adotar um viés de protesto, se pareceu muito mais com uma espécie de "lamento resignado perante a incompreensão dos conservadores" ${ }^{8}$. Incompreensão esta que pode ser evidenciada através do artigo assinado por Tristão Ribas que fora publicado no jornal A Notícia (RJ), que, aliás, é o único texto crítico sobre A pintura em pânico que data do mesmo ano de sua publicação, 1943. No referido artigo, além de considerar a fotomontagem como "uma besteira à custa dos outros, sem nenhum mérito" ${ }^{9}$, Ribas ataca pessoalmente Jorge de Lima ao se referir ao alagoano como "médico

\footnotetext{
${ }^{5}$ Amaral JR (1938) - Jorge de Lima, fotografo supra-realista, não paginado.

${ }^{6}$ Idem, ibidem.

7 Idem, ibidem.

${ }^{8}$ Sacchettin, 2018, p.43.

${ }^{9}$ Citado por Sacchettin, p.44
} 
importante e poeta modernista que também se entrega às vezes a divertimentos pictóricos em estilo de criança." ${ }^{10}$ Segundo Sacchettin, as desqualificações atribuídas ao poeta e às fotomontagens podem ter sido motivadas pela pequena reincidência de algumas figuras desnudas ao longo do livro, e, principalmente, pela única composição comentada ao longo do artigo, "Será revelado no final dos tempos", sobre a qual o colunista discorre:

Que quer dizer por exemplo o sr. dr. Jorge de Lima com aquele homem com cara de burguês grave e sisudo engolindo um bicho que pelos modos teria sido um carneiro? Será um símbolo? Não se sabe. O que se vê, entretanto, é que o autor de tesoura em punho ajeitou as figuras de maneira a dar ao boneco uma feição bandalheira. O carneiro, de nádegas raspadas à moda de cabeça de alemão, só a força de muito olhar é que é carneiro. À primeira vista não passa de uma reprodução fidedigna de certo objeto obsceno muito usado em Pompeia da antiguidade ${ }^{11}$.

Figura 3 - Será revelado no final dos tempos.

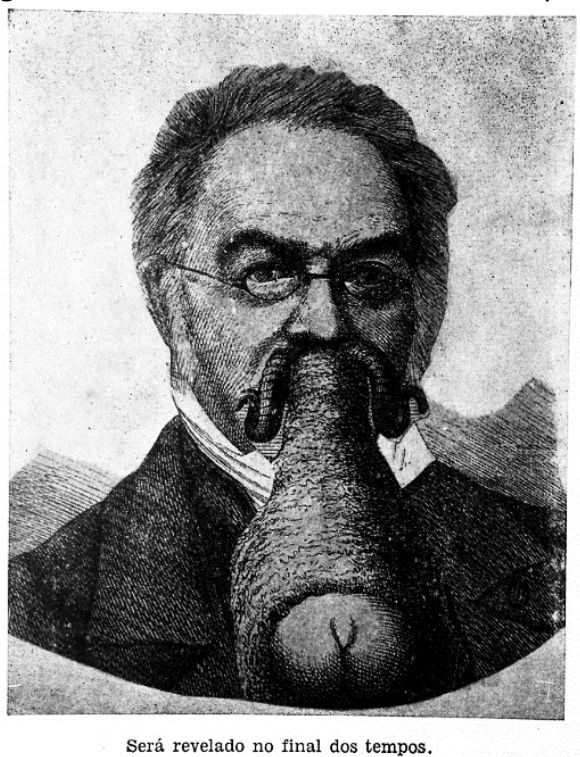

Fonte: Jorge de Lima (1943).

Segundo Annateresa Fabris (2011 p.17), as novas referências visuais e fotográficas do início do século XX foram se inserindo no Brasil através de episódios específicos que, por mais que se tratem de experiencias isoladas, contribuíram muito para "a revisão dos postulados fotográficos vigentes no Brasil", que àquela altura ainda estariam "atrelados à concepção pictorialista". As fotomontagens de Jorge de Lima são justamente um desses momentos pontuais em que ocorre uma abertura às novas

\footnotetext{
${ }^{10}$ Idem, ibidem.

${ }^{11}$ Citado por Sacchettin, p.44
} 
possibilidades fotográficas, nos colocando em "diálogo com o horizonte tecnológico". A recepção negativa de A pintura em pânico (1943) por Tristão Ribas situa-se inegavelmente neste contexto particular brasileiro, ainda não ambientado às novas possibilidades fotográficas, porém, ocorre efetivamente por conta daquilo que Annateresa Fabris $\left(2002\right.$, p.147) ${ }^{12}$ chamou de cerne crítico da fotomontagem, que ocasiona uma espécie de "desambientação mental", por conta da:

utilização de um análogo da realidade em sentido ilusionista, de maneira a criar imagens inéditas não apenas pelas distorções dimensionais de vários personagens e objetos, mas sobretudo pelas aproximações arbitrárias e enigmáticas, que trazem o princípio da metamorfose para o interior do processo fotográfico.

Neste sentido, é possível relacionar este estado perceptivo "desambientado" suscitado pela fotomontagem ao conceito de Shock, em A obra de arte na era de sua reprodutibilidade técnica (1936), de Walter Benjamin, atribuído por ele à percepção convocada pelo cinema. Segundo Benjamin, o Shock ocorre pela necessidade de uma imediata readaptação do olho, e, portanto, da percepção, às sucessivas imagens que se projetam em uma espécie de sobreposição fugaz.

Compare-se a tela em que se projeta o filme com a tela em que se encontra o quadro. Na primeira, a imagem se move, mas na segunda, não. Esta convida o espectador à contemplação; diante dela, ele pode abandonar-se às suas associações. Diante do filme, isso não é mais possível. Mas o espectador percebe uma imagem, ela não é mais a mesma. Ela não pode ser fixada, nem como um quadro nem como algo de real.

A associação de ideias do espectador é interrompida imediatamente, com a mudança da imagem. Nisso se baseia o efeito de choque provocado pelo cinema, que, como qualquer outro choque, precisa ser interceptado por uma atenção aguda. (BENJAMIN, 1955)

No choque proporcionado pela fotomontagem, do mesmo modo, quando se percebe um elemento, ele já não é o mesmo, já que fora deslocado, fragmentado e ressignificado. E por se utilizar da fotografia e subvertê-la, a fotomontagem, da mesma maneira, "não pode ser fixada, nem como um quadro, nem como algo de real". E ainda, num primeiro momento, a associação de ideias é constantemente interrompida, em razão da modificação estrutural do elemento em si e da união de fragmentos díspares que, ao serem fundidos, evocam tanto a unidade quanto a fragmentação das partes, tal como ocorre à visão em decorrência da sucessão de frames. Deste modo, o shock provocado pela fotomontagem é semelhante ao proporcionado pelo cinema pelo fato de, tanto um quanto o outro, derivarem da fotografia, que é, ao menos em gênese, o meio através do qual se

12 Fonte: Fotomontagem e surrealismo. In: REVISTA USP, São Paulo, 2002, n.55. Disponível em: http://www.revistas.usp.br/revusp/article/viewFile/35154/37874 
pretende a apreensão da realidade. Sob este prisma, a fotomontagem pode ser entendida como uma afronta, maior ainda que o cinema, à pintura. A divisão, através do recorte, dos elementos que compõem uma fotografia, e a posterior composição de uma nova imagem a partir desses fragmentos, promove ou incita uma atitude poética, que, pelo menos em essência, é inerente à atividade pictórica ${ }^{13}$. Neste sentido, o modo de compor uma fotomontagem se assemelha ao modo de pintar, no que tange à estruturação de planos, à disposição dos elementos no espaço, e sobretudo, à carga simbólica tão cara e típica da pintura. E, ainda, a fotomontagem, por ter sido utilizada no contexto das vanguardas históricas como uma alternativa aos preceitos limitantes do abstracionismo pictórico, acabou por evitar um movimento de retorno à pintura figurativa. (ADES, 1976, p.15) Segundo Sacchettin (2018, p.131), o pânico experimentado pela pintura em A pintura em pânico (1943), ocorre, em certa medida, pelo fato de que, realmente, a fotomontagem coloca "em xeque um já estabelecido sistema de representação, perturbando a figuração a partir da própria figuração". De fato, a fotomontagem desarticula, fragmenta, descola e realoca elementos, e faz disso uma desvirtuação daquilo que pode ser entendido como conceito fundamental da fotografia. Surge como autêntica arte de vanguarda e, justamente por isso, anuncia, em vários níveis, um possível rumo para o qual se direciona a trajetória da Arte. O potencial tecnológico devastador anunciado pela primeira guerra, a condição assombrada e aturdida que as guerras impõem à consciência humana, a noção de fragmentação da realidade endossada pelo cenário desmoronado resultante dos conflitos e o prenuncio da inevitável decadência do ideal de "progresso", coincide, não por acaso, com um período de grande produção de fotomontagens. Parece que a técnica se comporta como uma espécie de alusão ao cenário dissociado no qual emerge. Entretanto - e aqui pode-se dizer que a fotomontagem transcende a si mesma -, parece materializar plasticamente a condição que Lyotard (1986) primeiramente definiu como "pós-moderna"14, conceito este que não encerra uma definição única, pois, justamente, está relacionada a uma espécie de rompimento com qualquer conceito totalizante.

\section{A PÓS-MODERNIDADE}

Considera-se pois, aqui, o conceito de pós-modernidade através da conceituação de Gianni Vattimo em A sociedade transparente (1992), que percebe que este termo encontra-se adstrito ao

\footnotetext{
${ }^{13}$ Ou a qualquer atividade artística.

${ }^{14}$ A condição pós-moderna (1979).
} 
fato de que, por conta do advento e consequente processo irrefreável de expansão dos meios de comunicação em massa, este tempo e sociedades - contemporâneos - estão, justamente, inseridos num contexto de comunicação generalizada, a sociedade do mass media. Para Vattimo, a modernidade, ou os ideais levados a cabo durante o período que oficialmente iniciou-se no fim do séc. XV e perdurou até meados da década de 1950-80 teve um fim, ou, ao menos, perdeu credibilidade, sofrendo inclusive alterações semânticas a ponto de não mais ser considerada, tal como em sua época, uma espécie de valor determinante. Um dos fatores essenciais para a composição do espectro da modernidade é a ideia do progresso, advinda sobretudo do lluminismo e largamente explorado nas utopias, que parte de uma concepção linear e do ideal emancipatório da história humana. Foi a partir desta concepção que adveio a noção do artista enquanto gênio criador, encarregado de engendrar o ineditismo, instaurando assim um culto cada vez mais intenso pelo novo. Sob a ótica do progresso, o valor acresce à medida que aquilo que se julga encontra-se em estágio mais avançado ou mais próximo da conclusão do processo (de evolução). Entretanto, este conceito regressa à concepção de história unitária que fora radicalmente criticada entre os séculos XIX e XX, e teve seu caráter ideológico denunciado e, em certa medida, rejeitado, tendo, por isso, caído em depreciação na esfera filosófica. Walter Benjamin observou, em suas Teses da Filosofia da História (1938), que a história única foi um mecanismo construído no passado pelos detentores do poder, o que não poderia ser diferente, visto que tais grupos intencionam à dominação gradativa e geral da sociedade no contexto da lógica irrefreável de expansão de seu próprio poder. Por isso mesmo, os relatos históricos são geralmente construídos de modo cronológico ou circunstanciais, em sua maioria tendenciosos e manipulados, e, principalmente, sob a ótica do que interessa aos detentores do poder, excluindo completamente as histórias adjacentes, ou aquelas que colocam em xeque, ainda que minimamente, as fundações do sistema de dominação.

Assim, aquilo de que fala a história são as vicissitudes da gente que conta, dos nobres, dos soberanos, ou da burguesia quando se torna classe de poder: mas os pobres, ou os aspectos da vida que são considerados <<baixos>>, não <<fazem história>>. (VATTIMO, p.9, 1992)

Por tudo o que ocorreu no contexto da primeira metade do século XX e até mesmo antes, a concepção de história como curso unitário fora sendo paulatinamente abandonada, e, com isso, o ideal de progresso, que só pode advir de tal concepção, também entrou em crise. Já que não existe um sentido social singular para onde se dirige e em função do qual se desenvolvem os acontecimentos e preocupações humanas, não é possível "sustentar que eles se dirigem para um 
fim, que realizam um plano racional de melhoramento, educação, emancipação." Não é possível porque não é lógico sustentar que evolução e progresso emergem do massacre, da barbárie tecnológica e do domínio do homem pelo homem. Mediante isto, também não faz sentido sustentar que o atual período seja moderno, já que, mesmo que os resquícios daqueles totalitarismos ainda estejam profundamente enraizados na sociedade, a noção de diversidade, característica da tal condição "pós-moderna", está sendo cada vez mais bem assimilada. Neste sentido, e no que tange especificamente à experiência estética na "existência tardomoderna", Vattimo propõe uma analogia entre o já citado conceito de Shock em A obra de arte na era de sua reprodutibilidade técnica de Walter Benjamin e o Stoss, em A origem da obra de arte, de Martin Heidegger, dando ênfase ao fato de ambas as obras terem sido publicadas no ano 1936.

Para Vattimo, o texto de Benjamin tem sua intuição central na noção da modificação do Wesen (essência) da arte, e é a partir dele que se fundam as bases da noção de que a arte já não comporta mais, exclusivamente, uma finalidade metafísica, de modo que a recepção estética tal como fora considerada de Aristóteles a Hegel não faz mais sentido, ou pelo menos não tem mais condições de ser considerada como o único modo pelo qual tal fenômeno ocorre e pode ser explicado. (VATTIMO, p.52-53, 1992)

Em Heidegger, por exemplo, se desenvolve a noção da arte enquanto "realização da verdade", que se constitui a partir do conflito entre a exposição do mundo e a produção da terra. Onde "o mundo exposto pela obra é o sistema de significados que ela inaugura" de modo que "a terra é produzida pela obra quando é apresentada, mostrada como o fim obscuro, nunca totalmente consumável em enunciados explícitos, sobre a qual o mundo da obra se radica." (VATTIMO, 1992, p.59) O Stoss (choque) é o efeito do contato entre o observador e uma obra assim produzida. Em Benjamim, como visto, o Shock é aplicado particularmente ao cinema. Vattimo aproxima estes dois conceitos no intuito de possibilitar um alcance aos "aspectos essenciais da nova 'essência' da arte na sociedade tardo-industrial". Observa o filósofo que uma das proposições de Benjamin relaciona a percepção necessária ao cinema àquela exigida ao pedestre moderno, que, ao caminhar pelas ruas, é compelido a manter-se em alerta e, portanto, abriga uma sensação de perigo constante, devido à probabilidade de perder a vida em um atropelamento. Também em Heidegger, no Stoss, é possível encontrar a relação entre o choque (na arte) e a morte, "não tanto ou não principalmente com o risco de ser atropelado por um autocarro na rua, mas com a morte como possibilidade constitutiva 
da existência". Para Heidegger, a obra de arte ocasiona tal impacto pelo fato de constituir-se como existência ("ser mais do que não ser"). Vattimo relaciona o conceito de angústia presente em O Ser e o Tempo e o Stoss, para indicar que a experiência estética é, também, uma experiência de desenraizamento e, ainda, que o contato com a obra de arte é similar ao encontro com uma pessoa cujos ideais não correspondem à visão de mundo que se tem, solicitando uma posição interpretativa do observador.

É antes de mais nesse sentido que se deve entender a tese de Heidegger segundo o qual a obra de arte funda um mundo, dado que se apresenta como uma nova <abertura> históricoeventual do ser. (VATTIMO, p.56, 1992)

Sumariamente, a relação estabelecida por Vattimo entre o shock e o stoss advém da concepção de que estes dois conceitos partilham a noção do desenraizamento, que é compreendido como uma consequência direta da necessidade de estruturação e adaptação imediata ao universo que é exposto e ao ambiente criado por ele , que se impõe através do estranhamento. Confronta-se, então, a noção de enraizamento, predominante de Aristóteles a Hegel, que conceitua o objetivo ou função da obra de arte através de formulações metafísicas e, ainda, a entende como lugar de segurança (Geborgenheit). A partir destas formulações e aproximações, Vattimo busca oferecer uma compreensão cabível daqueles dois conceitos - fundamentais ao entendimento da transformação receptiva e, portanto, da própria obra de arte - em um momento crucial para a teoria estética, que foi o advento da sociedade de comunicação generalizada. A partir disso, Gianni Vattimo (1992) propôs a formulação de uma concepção estética que compreenda e se desenvolva a partir da consciência do "desenraizamento" e da noção da "oscilação" propiciados pelo contato com a obra, entendendo-os como aspecto constitutivo e não provisório da arte. A consequente modificação da recepção estética, a quebra das narrativas totalizantes e o desprestígio dos cânones, são, no entendimento de Vattimo, consequências de uma sociedade desacreditada dos ideais modernos e que, portanto, busca outras formulações para compreender-se. Neste sentido, entende-se que a fotomontagem pode ser considerada como uma técnica de aspiração pós-moderna, por apresentar uma alternativa ao molde canônico de composição pictórica - a pintura - utilizando-se, como se viu, de elementos que atacam a realidade a partir da própria figuração. "No fundo, cada fragmento é um desvio, um antídoto para essa totalidade examinada como canônica e insuficiente" (MONTEJO NAVAS, p.47, 2017). 
Recorrendo à conceituação supracitada, proposta por Gianni Vattimo, percebe-se que na obra de Jorge de Lima, o stoss proporcionado pelo contato com as fotomontagens é emitido desde o momento introdutório da obra e progride no decorrer do livro, quando o receptor entra em contato com um universo que o remete a diversas realidades, e, ao mesmo tempo, funda um mundo que não se define ou que não comporta uma única definição, configurando-se, portanto, como uma arte oscilante, por proporcionar um desenraizamento continuo, ou ainda que se apresenta de maneira distinta a cada novo contato com a obra. Ao empregar o uso da fotografia e indicar que a pintura estaria em pânico, Jorge de Lima ainda suscita uma outra questão pertinente do Surrealismo, que se utilizou dos recursos fotográficos mais do que qualquer outro movimento de vanguarda. Neste sentido, Rennó Assunção (2005-2006, p.62), em Fotomontagem e colagem poética em Jorge de Lima, observa que o pânico da pintura pode ter sido desencadeado pela simplicidade da técnica da fotomontagem que, mesmo sendo acessível, não significou que apresentasse inferioridade em relação à pintura (figurativa ou não) em termos de qualidade plástica ou estética. Por este mesmo viés, Annateresa Fabris indica que a técnica, ainda que simples:

\footnotetext{
Não deixa de apresentar elementos conceituais que permitem vislumbrar o desenvolvimento de uma nova sensibilidade plástica ao alcance de todos, uma ampliação da experiência da visão, o encontro do estético e do político, uma nova concepção de conhecimento, um novo momento na história da humanidade no qual o homem "talvez possa destruir e construir ao mesmo tempo." (2002, p.149)
}

Neste sentido, no intuito de transpor os elementos conceituais supracitados, observando as indicações de Panofsky, faz-se oportuno observar brevemente algumas especificidades de pelo menos uma das fotomontagens que integram A pintura em pânico, já que a observação de outras mais se faz inviável em apenas um artigo. Sendo assim, observaremos a fotomontagem que inaugura o conjunto por ser justamente a primeira e, portanto, se constituir inevitavelmente como uma espécie de gênese, operando, deste modo, como parâmetro ao entendimento de quem percorre ou busca uma interpretação do livro como um todo, já que, como diria Heidegger, "A origem de algo é a proveniência de sua essência" (1977, p.11).

\section{UM EVENTUAL AGRUPAMENTO DAS IMPRESSÕES}


Figura 4 - Primeira fotomontagen de A pintura em pânico.

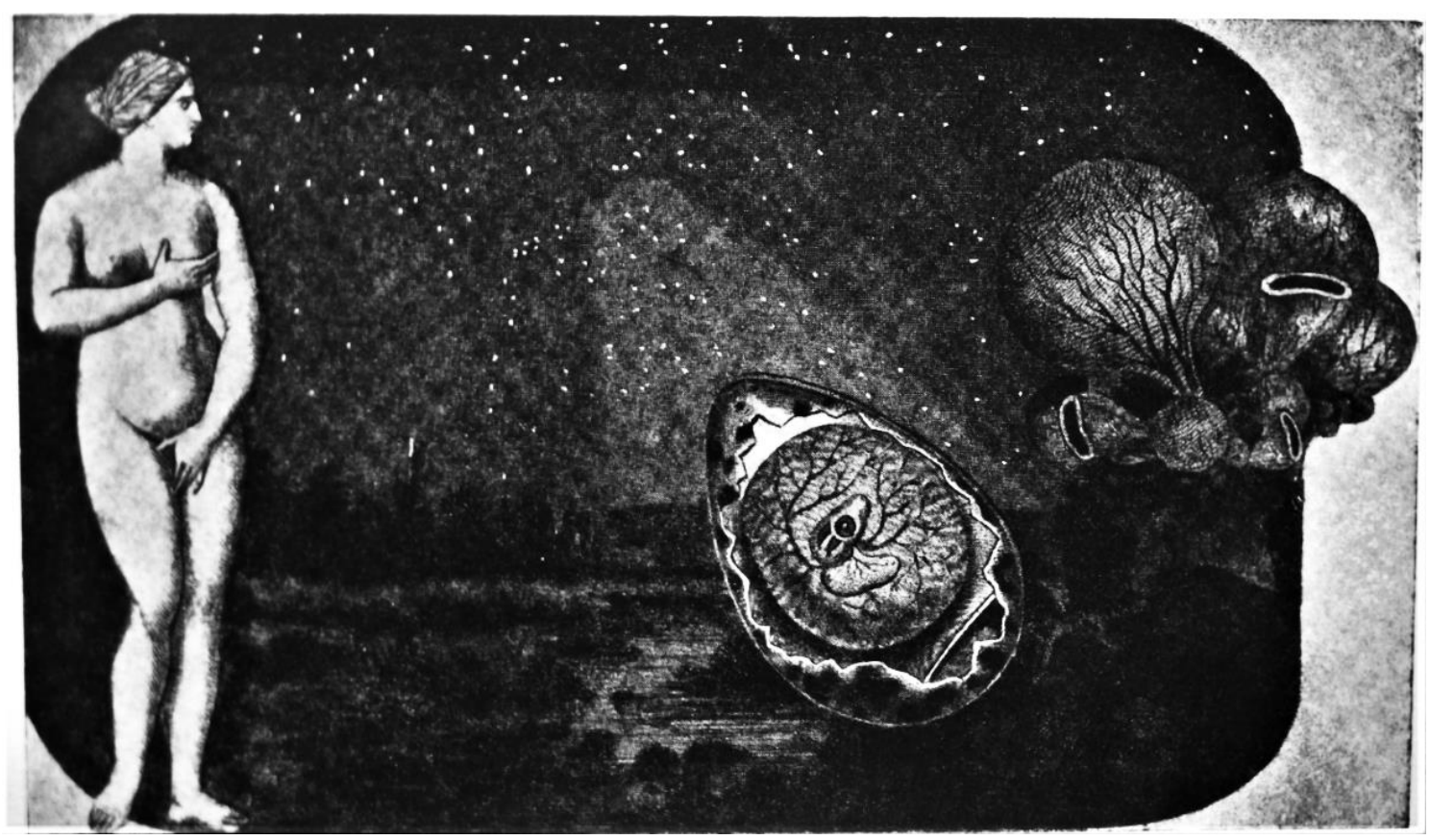

Fonte: Jorge de Lima (1943).

A primeira fotomontagem de A pintura em pânico (1943) (Fig.4), é composta em primeiro plano por três figuras, que à primeira vista parecem não ter qualquer relação entre si, sobre um plano de fundo também enigmático, sendo ainda possível observar uma espécie de moldura lateral sobre a qual ocorre a sobreposição de uma pequena parte de dois dos elementos. A figura feminina, com o olhar voltado para o centro da composição, parece observar os outros dois elementos: um ovo que reúne características mecânicas e biológicas, e uma espécie de composto de células que se assemelha à uma criatura marinha zoófita. (SACCHETTIN, 2018, p.119) Tal composição vem acompanhada, muito simbolicamente, da seguinte citação:

Puis il naquit d'un trombone et le trombone le nourrit pendant treize mois, puis il fut sevré et confié au sable qui s' éntendai partour car c'etait le desert, seul avec le chameau, puis il naquit d'une fémme et il fut grandemente étonné, et réfléchissaint sur son sein, il suçotait, il crachoutait, il ne savait plus quoi. (H. Michaux). ${ }^{15}$

No que tange ao texto, este primeiro instante pode ser percebido como uma necessidade de Jorge de Lima em exaltar a poesia, materializada na enunciação do poeta Henri Michaux (1899-1984), personalidade enigmática que certamente influenciou a referida obra, visto que sua passagem pelo

\footnotetext{
${ }^{15}$ Então ele nasceu de um trombone e o trombone o alimentou por treze meses, depois ele foi desmamado e colocado na areia, sozinho com o camelo, então ele nasceu de uma mulher e ficou muito surpreso, e refletiu sobre seu peito, elechupava, cuspia, não sabia mais o quê. (H. Michaux)
} 
Brasil proporcionou contato direto entre os dois artistas (SACCHETTIN, 2018, p.121). Note-se que a citação de Michaux e a própria composição reforçam, por outro lado, uma atmosfera transcendente, já que ele, assim como Jorge de Lima, foi uma espécie de místico, e suas biografias guardam ainda outras similaridades. (SACCHETTIN, 2018, p.120) Entretanto, o que importa aqui indicar é que, ao iniciar o livro com uma citação, Jorge de Lima faz expressa menção a outro poeta, e ainda o coloca como vertente - pelo menos de modo reflexo - por onde se possa percorrer a obra. Tal atitude, provavelmente consciente, visto que o poeta tinha uma personalidade profundamente intelectual, é entendida aqui como uma espécie de rejeição à concepção de ineditismo e de gênio artístico, ao mesmo tempo em que estabelece uma mediação entre Michaux e uma composição que decorre de seus escritos ou a eles remete. Como se vê, Jorge de Lima se apropria do texto do poeta belga, do mesmo modo que se apropria das imagens que foram utilizadas para compor a fotomontagem, de modo que o mundo fundado a partir daí surge de uma dupla apropriação, de imagem e texto, e é exposto sobre uma única "terra", sobre a qual se radica um mundo composto de fotografia e poesia.

Aliás, se a citação se refere a um mundo e a fotomontagem disto deriva, Jorge de Lima assume direções surrealistas em essência e pós-moderna por virtude. Se, ao fundar um mundo, expõe-se o que dele decorre a partir da criação de uma terra, Jorge de Lima parece fundar um mundo, conscientemente, através de outrem, demonstrando reverência a quem alude ou, por isso mesmo, uma consciência da constituição referencial de sua obra, sendo a exposição da terra aí, um mecanismo cíclico que remete a Michaux e a Jorge de Lima, e, ainda, os coloca como interlocutores de experiências universais, vide a representação do nascimento, a experiência universal por excelência, expressa. "Puis il naquit d'un trombone... puis il naquit d'une fémme... Então ele nasceu de um trombone... então ele nasceu de uma mulher".

A disposição espacial dos elementos parece evidenciar um suposto vazio que existe entre a vida e a fonte da vida, sendo a vida representada por um ovo formado por uma casca notadamente mecânica que, contudo, abriga uma essência orgânica. O que pode ser entendido, dentre infindáveis interpretações, como uma analogia à vida moderna que tenta, ininterruptamente, recriar-se através de tecnologias, mas que, entretanto, não pode alterar o fato de que existe em um ambiente fundamentalmente natural. A noção de ambiente, aliás, assim como a de tempo, é indefinida, não sendo possível saber onde nem quando ocorre a cena fixada na fotomontagem, o que, por sua vez, nos remete a oscilação, que incorre no desenraizamento, comum ao stoss e ao shock, e que tem a 
ver com "a experiência de estranhamento, que exige um trabalho de recomposição e de readaptação" (VATTIMO, 1992, p.57). Justamente, a todo tempo, as fotomontagens parecem convocar uma readaptação do olho e a recomposição do sentido, e, igualmente, a readaptação do sentido e a recomposição perceptiva, funcionando assim como uma projeção, um revide, que se lança sobre quem a recepciona, eliminando a possibilidade de funcionar como um lugar de segurança.

É possível, portanto, experimentar, uma sensação suscitada pela disposição (e tensão) dos elementos, emergida do interior da própria fotomontagem, que se constitui como uma espécie de estranhamento duplicado que produz uma oscilação perceptiva. Com efeito, A pintura em pânico (1943) não parece proporcionar um enraizamento ou provocar em quem a recepciona uma sensação de estabilidade, caracterizando-se assim como uma obra da qual é plenamente possível se dizer que convoca uma experiência estética que desemboca da condição tardo moderna, onde a única permanência é a mutabilidade do sentido. (VATTIMO, 1992, p.64) A obra revela a si mesma, ainda, pela técnica que lhe é inerente, a fotomontagem, como um agrupamento de visões de mundo que se constitui de inúmeras possibilidades, sem prejuízo do conteúdo fundamental das mesmas, demonstrando, através da composição material, uma abstração teórica, qual seja, a da consciência que perpassou os ideais modernos e se constitui a partir da experimentação de realidades diversas que, ao serem justapostas, compõem um todo híbrido. Afinal, a fotomontagem, além de suscitar o shock, inevitável à atividade criativa deste tempo, propicia um desenraizamento e desencadeia a oscilação, funcionado como uma técnica que, curiosamente, agrega aquilo que fragmenta, do mesmo modo que aquela consciência - ao que tudo indica transitória - que experimentou ou experimenta a sociedade de um tempo em mutação, que não mais comporta, legitima ou exalta ideais excludentes, mas que sobretudo, pressupõe e abriga a coexistência das múltiplas visões de mundo que, fundamentalmente, o compõem.

\section{CONSIDERAÇÕES FINAIS}

Isto posto, é necessário esclarecer que as convergências indicadas no presente artigo decorreram de uma possibilidade percebida no decorrer de uma pesquisa maior que investiga, através do método iconológico, a obra A pintura em pânico. Foi proposta, portanto, uma aproximação entre a técnica da fotomontagem e o conceito de pós-modernidade em Gianni Vattimo, 
para quem o shock, por ele conceituado através do Stoss de Heidegger e do Shock de Benjamin, e o desenraizamento que ocorre pelo fato de a arte não proporcionar mais um lugar de segurança para quem com ela se depara, levam inevitavelmente ao processo oscilatório que, por sua vez, é uma condição particular da pós-modernidade. Observou-se, assim, que a técnica da fotomontagem parece ter ultrapassado o período no qual emergiu, no sentido de ser uma técnica que parece materializar a consciência pós-moderna, constituída, principalmente, da noção de que as diversas visões de mundo que compõe um ambiente são justamente a substância daquilo que se entende por sociedade, e que, portanto, não se afigura lógico sustentar que uma única idealização seja o parâmetro em torno do qual todos os integrantes de um determinado contexto sejam obrigados a se movimentar. Deste modo, entende-se que a consciência pós-moderna, que resultou do desmoronamento da sociedade moderna, se constitui como uma possibilidade de reconstrução a partir do próprio estilhaço, tal como a fotomontagem, que por sua vez, é uma técnica que busca primeiramente desarticular elementos para então compor através do fragmento. Por fim, compreende-se A pintura em pânico, que é, sem dúvidas, uma obra bastante singular no contexto do Modernismo brasileiro do fim da década de 30 e início da década de 40, como uma obra que transcendeu à sua época, sem prejuízo dos valores simbólicos, por se utilizar de uma técnica que, ainda que surgida no século XIX e reformulada no contexto das vanguardas, faz analogia à consciência pós-moderna, por indicar, tal como, a título de exemplo, em sua composição inicial, muito simbolicamente, um despojamento de parâmetros substancialmente modernos, e pelo inevitável shock e a consequente oscilação perceptiva que as fotomontagens que a integram ocasionam a quem as recepciona, o que sugere que esta obra seminal de Jorge de Lima possa estar situada na fonte da poética da pós-modernidade no contexto da arte brasileira..

\section{REFERÊNCIAS}

ADES, D. Photomontage. New York: Pantheon Books, 1976.

AMARAL JR., A. Jorge de Lima, fotógrafo supra-realista. O Cruzeiro, Rio de Janeiro, n. 36, 9 jul. 1938, p. 5 e p. 12. Disponível em: http://memoria.bn.br/DocReader/003581/23298. Acesso em: 25 fev. 2020. 
ASSUNÇÃO, T. R. Fotomontagem e colagem poética em Jorge de Lima. Éspeculo: revista de estudios literários, Madri, ano 10, n. 31, nov.- fev., 2005-2006. Disponível em:

http://www.ucm.es/info/especulo/numero31/jorlima.html. Acesso em: 02 mar. 2020.

BENJAMIN, W. A obra de arte na era de sua reprodutibilidade técnica. 1955. Website PhilArchive. Disponível em: https://philarchive.org/archive/DIATAT Acesso em: 27 fev. 2020.

ERNST, M. The Hundred Headless Woman (La Femme 100 têtes), 1929. Website MoMA. Disponível em: https://www.moma.org/collection/works/229544 Acesso em: 12. mar. 2020.

EXPOSIÇÃO CAIXA CULTURAL RIO. A Pintura em Pânico: fotomontagens Jorge de Lima. Rio de Janeiro, 15 mar. - 03 maio, 2010. Website Rio \& Cultura. Disponível em:

http://www.rioecultura.com.br/expo/expo_resultado2.asp?expo_cod=1486. Acesso em: 28 fev. 2020.

FABRIS, A. Fotomontagem e surrealismo: Jorge de Lima. Revista USP, São Paulo, n. 55, p. 143-151, 30 nov. 2002. DOI: https://doi.org/10.11606/issn.2316-9036.v0i55p143-151. Disponível em: http://www.revistas.usp.br/revusp/article/view/35154 Acesso em: 20 fev. 2020.

FABRIS, A. O desafio do olhar: fotografia e artes visuais no período das vanguardas históricas. São Paulo: Editora WMF Martins Fontes, 2011. v.2

FERNANDES, M. L. B. R. A Fotomontagem no Seculo XIX: da mecânica à narratologia. Revista Rhetorikê, Portugal, n. 4, p. 37-76, maio de 2012. Disponível em:

http://www.rhetorike.ubi.pt/04/pdf/Rhetorike-04-03-fernandes.pdf. Acesso em: 19 fev. 2020.

HEIDEGGER, M. A origem da obra de arte. Lisboa: Edições 70, 1977.

LIMA, J. de. A pintura em pânico. Rio de Janeiro: [s. n.], 1943.

LYOTARD, J.-F. A condição pós-moderna. São Paulo: José Olympio, 1986.

MACHADO, L. Fotografia da capa do original n.177 de A pintura em pânico (1943). Biblioteca Brasiliana Guita e José Mindlin.

MONTEJO NAVAS, A. Fotografia e poesia (afinidades eletivas). São Paulo: Ubu Editora, 2017.

PANOFSKY, E. O Significado nas artes visuais. São Paulo: Perspectiva, 2014.

SACCHETTIN, P. A pintura em pânico: fotomontagens de Jorge de Lima. 2018. Tese (Doutorado em História) - Programa de Pós-Graduação em História, Universidade Estadual de Campinas, Campinas, SP, 2018. Disponível em: http://www.repositorio.unicamp.br/handle/REPOSIP/331878. Acesso em: 25 fev. 2020. 
A pintura em pânico, a fotomontagem e a pós-modernidade

Lorena Machado Macêdo Oliveira, Luciane Viana Barros Páscoa

VATTIMO, Gianni. A sociedade transparente. Lisboa: Relógio D'água, 1992. 